\title{
Atividade antibacteriana de Óleos Essenciais sobre Streptococcus mutans e Staphylococcus aureus
}

FREIRE, I.C.M.1*; PÉREZ, A.L.A.L.'; CARDOSO, A.M.R.'; MARIZ, B.A.L.A.'; ALMEIDA, L.F.D.'; CAVALCANTI, Y.W. ${ }^{3} ;$ PADILHA, W.W.N. ${ }^{4}$

Universidade Federal da Paraíba, Campus Universitário, S/N, Cidade Universitária. CEP: 58.051-900 - João Pessoa, PB - Brasil. *icmf_jp@hotmail.com. 2Universidade Estadual de Campinas, Faculdade de Odontologia de Piracicaba, Departamento de Prótese e Periodontia - Piracicaba-SP, Brasil. Av. Limeira, 901 Caixa Postal 52 - Piracicaba - SP CEP 13414-903 . 'Universidade Estadual Paulista, Faculdade de Odontologia de Araraquara, Departamento de Dentística Restauradora, Araraquara-SP, Brasil. Rua Humaitá, 1680 - Araraquara - CEP:14801903. “Universidade Federal da Paraíba, Departamento de Clínica e Odontologia Social. Campus Universitário, S/N, Cidade Universitária. CEP: 58.051-900 - João Pessoa, PB - Brasil

RESUMO: Este trabalho objetivou avaliar a ação antimicrobiana in vitro dos óleos essenciais de Ocimum basilicum (Manjericão Exótico), Thymus vulgaris (Tomilho Branco), e de Cinnamomum cassia (Canela da China) sobre cepas bacterianas de Streptococcus mutans (ATCC 25175) e Staphylococcus aureus (ATCC 25923). A atividade antibacteriana dos óleos essenciais foi determinada pela Concentração Inibitória Mínima (CIM) e a Concentração Bactericida Mínima (CBM) através da técnica de microdiluição e do esgotamento. Para a CIM, foram utilizadas placas de 96 poços e inseriu-se $100 \mu \mathrm{L}$ de caldo $\mathrm{BHI}, 100 \mu \mathrm{L}$ da diluição dos óleos essenciais no primeiro poço e $10 \mu \mathrm{L}$ da suspensão bacteriana $\left(1,5 \times 10^{\circ}\right.$ microrganismos/ $\mathrm{mL}$ ). Realizou-se a diluição seriada partindo-se da concentração inicial de $8 \%$ até $0,0625 \%$. A CIM correspondeu à última diluição na qual não foi verificada a presença de bactérias. Para obter a CBM, realizou-se a semeadura em Ágar Miller-Hinton das diluições correspondentes a $\mathrm{CIM}, 2 \mathrm{CIM}$ e $4 \mathrm{CIM}$. As placas foram incubadas a $37^{\circ} \mathrm{C}$ em estufa bacteriológica por 24 horas. Os testes foram realizados em triplicata tendo a clorexidina como controle positivo. Para $S$. aureus (ATCC 25923) a CIM e CBM dos óleos essenciais de $C$. cassia, $O$. basilicum e $T$. vulgaris foram 0,0625\%, 4\% e 0,0625\%, respectivamente. Para S. mutans a CIM e a CBM dos óleos essenciais de C. cassia e T. vulgaris foram $0,125 \%$ e $0,25 \%$, respectivamente. Já a CIM do O. basilicum foi $4 \%$ e não apresentou ação bactericida. Conclui-se que os óleos essenciais avaliados apresentaram ação antibacteriana frente a cepas de $S$. mutans e $S$. aureus, sendo que os menores valores de CIM e de CBM foram provenientes dos óleos de C. cassia e T. vulgaris.

Palavras-chave: Streptococcus mutans, Staphylococcus aureus, Microbiologia.

ABSTRACT: Antibacterial Activity of Essential Oils against Strains of Streptococcus and Staphylococcus: The aim of this study is to evaluate the in vitro antimicrobial activity of essential oils of Ocimum basilicum (basil), Thymus vulgaris (thyme) and Cinnamomum cassia (Chinese cinnamon) against strains of Streptococcus mutans (ATCC 25175) and Staphylococcus aureus (ATCC 25923). The antibacterial activity of the essential oils was determined by Minimum Inhibitory Concentration (MIC) and Minimum Bactericidal Concentration (MBC). The MIC was obtained by the microdilution technique using 96-well microplates, in which we inserted: $100 \mu \mathrm{L}$ of Brain Heart Infusion broth at double concentration, $100 \mu \mathrm{L}$ of the dilution of the essential oils and $10 \mu \mathrm{L}$ of bacterial suspension $\left(1.5 \times 10^{6}\right.$ organisms $\left./ \mathrm{mL}\right)$. The products were diluted from the initial concentration of $8 \%$ up to $0.0625 \%$. The MIC corresponded to the last dilution in which there was no presence of bacteria or turbidity in the culture medium. The MBC was obtained by seeding, in Mueller-Hinton agar, $10 \mu \mathrm{L}$ aliquots of dilutions corresponding to the MIC and the two immediately preceding ones (2MIC and 4MIC). The plates were incubated at $37^{\circ} \mathrm{C}$ in a bacteriological incubator for 24 hours. The tests were performed in triplicate, and $2 \%$ Chlorhexidine Digluconate was the control product. For S. aureus, the MIC and MBC of the essential oils of C. cassia, O. basilicum and T. vulgaris were $0.0625 \%, 0.0625 \%$ and $4 \%$, respectively. For S. mutans, the MIC and MBC of the essential oils of $C$. cassia and $T$. vulgaris 
were $0.125 \%$ and $0.25 \%$, respectively. The MIC of O. basilicum against $S$. mutans was $4 \%$ and the essential oil showed no bactericidal action. Chlorhexidine Digluconate presented antibacterial activity against all organisms. The evaluated essential oils presented antibacterial activity against the strains of $S$. mutans and $S$. aureus, and we highlight the essential oils from $C$. cassia and T. vulgaris with the lowest MIC and MBC.

Keywords: Streptococcus mutans, Staphylococcus aureus, Microbiology, Antimicrobial agents/ inhibitors.

\section{INTRODUÇÃO}

As plantas medicinais estão sendo cada vez mais utilizadas para o tratamento de doenças, a fim de diminuir as desvantagens trazidas pelo uso crônico de antimicrobianos, tal como a resistência desses microorganismos diante de substâncias sintéticas (Costa et al., 2009). Diversas plantas e óleos essenciais têm sido avaliados quanto à ação antimicrobiana, estando entre eles o Ocimum basilicum (Manjericão Exótico), Thymus vulgaris (Tomilho Branco) (Duarte, 2006) e Cinnamomum cassia (Canela da China).

O manjericão é uma planta medicinal pertencente à família Lamiacea e tornou-se importante na sociedade por apresentar utilização na cosmética, na alimentação e, devido as suas propriedades terapêuticas, na indústria farmacêutica (Costa et al., 2009). Martins et al., (2010) relataram que a atividade antimicrobiana do óleo essencial de manjericão está associada a seus constituintes metil chavicol e linalol, sendo assim, amplamente utilizado na medicina popular no combate às infecções bacterianas.

O Tomilho, também utilizado indústria alimentícia, apresenta significativo potencial antimicrobiano devido à presença de seu constituinte Timol (Pozzo et al., 2011). Já o Cinnamomum cassia (canela) possui atividade antimicrobiana devido à presença do aldeído cinâmico (Souza et al., 2010).

Os óleos essenciais de produtos naturais consistem na forma de apresentação que concentra a maior quantidade de fitoconstituintes com propriedades biológicas ativas (Pozzatti et al., 2009). Uma vez que esses produtos são de fácil acesso à população, vislumbra-se a possibilidade de futura aplicação clínica. Assim, o seu uso deve ser embasado pela literatura científica.

Os microrganismos Streptococcus mutans e Staphylococcus aureus adquirem relevância na área da saúde por estarem associados com o desenvolvimento de diversas infecções. Assim, o uso de produtos naturais para contribuir para obtenção de novas ferramentas terapêuticas. Nesse sentido, o objetivo do presente estudo foi avaliar a ação antimicrobiana in vitro dos óleos essenciais de Ocimum basilicum, Thymus vulgaris e Cinnamomum cassia sobre cepas bacterianas de S. mutans (ATCC 25175) e S. aureus (ATCC 25923).

\section{MATERIAL E MÉTODO}

Realizou-se um estudo de abordagem indutiva, com procedimento comparativo descritivo e técnica de documentação direta em laboratório (Lakatos \& Marconi, 2009).

As cepas de referência utilizadas no estudo foram Streptococcus mutans (ATCC 25175) e Staphylococcus aureus (ATCC 25923). Os microrganismos foram obtidos do Laboratório de Materiais de Referência do Instituto Nacional de Controle de Qualidade em Saúde (Fundação Oswaldo Cruz - FIOCRUZ, Rio de Janeiro - RJ, Brasil). As cepas foram reativadas em caldo $\mathrm{BHI}$ a $37^{\circ}$ C no Laboratório de Microbiologia Oral - Núcleo de Medicina Tropical do Centro de Ciências da Saúde da Universidade Federal da Paraíba. Para a condução do estudo, suspensões dos microrganismos foram preparadas em solução salina, sob a concentração $1,5 \times 10^{6}$ microrganismos $/ \mathrm{mL}$, equivalente ao tubo 0,5 da Escala de MacFarland.

Para avaliação antimicrobiana in vitro, foram utilizados óleos essenciais de Ocimum basilicum (Manjericão Exótico), Thymus vulgaris (Tomilho Branco) e Cinnamomum cassia (Canela da China), obtidos da empresa Ferquima ${ }^{\circledR}$ (Ind. e Com. Ltda) e da Empresa Viessence ${ }^{\circledR}$ (Florianópolis$\mathrm{SC}$, Brasil), as quais cederam Laudo Técnico com especificações (Quadro 1). Os óleos essenciais utilizados no presente estudo tem sua produção padronizada e com possibilidade de fácil acesso da população, o que justifica a sua utilização. A partir desses produtos, componentes bioativos podem ser identificados diante da sua atividade biológica. A atividade antimicrobiana dos óleos essenciais foi avaliada pela determinação da Concentração Inibitória Mínima (CIM), por meio da técnica da microdiluição e pela determinação da Concentração Bactericida Mínima, através da semeadura em placas de petri. Considerou-se a densidade das substâncias igual a $0,9 \mathrm{~g} / \mathrm{mL}$, conforme especificações do fornecedor (Quadro 1). Os óleos essenciais foram diluídos em água destilada estéril, obtendo-se a concentração $16 \%$ considerada a solução-padrão inicial para todos os produtos avaliados. Para obtenção dessa concentração da solução-padrão inicial foram realizadas as seguintes

Rev. Bras. PI. Med., Campinas, v.16, n.2, supl. I, p.372-377, 2014. 
etapas descrita por Aligiannis et al. (2001) e Lima et al. (2006): foram adicionados, em tubos de vidro estéril, $0,8 \mathrm{~mL}$ do óleo essencial, $0,05 \mathrm{~mL}$ de Tween 80 e 4,2 mL de água destilada estéril; o conjunto foi agitado durante 5 minutos em aparelho agitador de soluções tipo Vortex (Mod. AP56, Phoenix), a fim de obter a concentração inicial de $16 \%$, equivalente a $144 \mathrm{mg} / \mathrm{mL}$. A utilização de Tween 80 foi efetiva para solubilização dos óleos essenciais em água, sem no entanto interferir na atividade biológica desses produtos, conforme verificado em estudos preliminares. Para avaliação da Concentração Inibitória Mínima (CIM), as soluções-padrão iniciais dos óleos essenciais foram diluídas de forma seriada, mediante emprego da técnica da microdiluição em placa de 96 poços (Aligiannis et al., 2011).

A determinação da CIM foi realizada em placas de microdiluição com 96 poços (ALAMAR®, Diadema, São Paulo, Brasil), dispostos em 12 colunas $(1$ a 12$)$ e 8 linhas $(\mathrm{A}$ a $\mathrm{H})$. Cada uma dessas placas destinou-se a análise de um microrganismo. As colunas 1, 2 e 3 foram destinadas a análise da ação antibacteriana do óleo essencial de Cinnamomum cassia; as colunas 4, 5, e 6 ao óleo essencial de Ocimum basilicum; e as colunas 7, 8 e 9, ao óleo essencial de Thymus vulgari. A coluna 10 foi destinada ao Controle de Esterilidade; a coluna 11 ao Controle de Crescimento; e a coluna 12 ao Controle positivo (Clorexidina).

Em cada um dos poços das placas de microdiluição foram inseridos $100 \mu \mathrm{L}$ de caldo $\mathrm{BHI}$ duplamente concentrado. Em seguida, inseriu-se $100 \mu \mathrm{L}$ das emulsões dos óleos essenciais para obtenção da concentração inicial de $8 \%$ (72,0 mg/ $\mathrm{mL}$ ) na primeira linha da placa de microdiluição. As concentrações subsequentes dos óleos essenciais foram obtidas após diluição seriada dos produtos naturais na placa de microdiluição, partindo-se da concentração inicial de $8 \%(72 \mathrm{mg} / \mathrm{mL}$ - Linha A) até $0,0625 \%($ Linha $H)$, pela transferência de $100 \mu \mathrm{L}$ do conteúdo ao poço subsequente. Para os poços da linha $\mathrm{H}$, foram dispensados $100 \mu \mathrm{L}$ do conteúdo, de modo a igualar o volume total de cada poço. As concentrações (em $\mathrm{mg} / \mathrm{mL}$ ) dos produtos analisados após a diluição seriada são apresentadas no Quadro 02.

Posteriormente, foram inseridos $10 \mu \mathrm{L}$ da
QUADRO 2. Diluições Seriadas dos Óleos Essenciais para técnica de avaliação antimicrobiana por microdiluição

\begin{tabular}{cc}
\hline Poços & Concentração $(\mathrm{mg} / \mathrm{mL})$ \\
\hline $1-A$ & $72 \mathrm{mg} / \mathrm{mL}$ \\
$2-B$ & $36 \mathrm{mg} / \mathrm{mL}$ \\
$3-C$ & $18 \mathrm{mg} / \mathrm{mL}$ \\
$4-D$ & $9 \mathrm{mg} / \mathrm{mL}$ \\
$5-E$ & $4,5 \mathrm{mg} / \mathrm{mL}$ \\
$6-F$ & $2,25 \mathrm{mg} / \mathrm{mL}$ \\
$7-G$ & $1,125 \mathrm{mg} / \mathrm{mL}$ \\
$8-H$ & $0,5625 \mathrm{mg} / \mathrm{mL}$ \\
\hline
\end{tabular}

suspensão dos microrganismos (1,5 × 107 UFC/mL) em todos os poços, exceto na coluna correspondente ao controle de esterilidade ${ }^{* *}$. Buscou-se, dessa forma, submeter todas as concentrações de produtos naturais avaliadas à mesma quantidade de microrganismos. As placas foram incubadas em estufa bacteriológica a $37^{\circ}$, por 48 horas. A CIM correspondeu à última diluição dos óleos essenciais na qual não foi verificada a presença de precipitado microbiano ou turvação no meio de cultura após o período de incubação.

A Concentração Bactericida Mínima (CBM) foi obtida por meio da semeadura, em Agar Mueller-Hinton, de alíquotas de $10 \mu \mathrm{L}$ das diluições correspondentes a CIM e duas imediatamente anteriores (2CIM e 4CIM) dos conteúdos dos poços das placas de microdiluição**. Essas concentrações imediatamente superiores a CIM são suficientes para demonstrar o efeito bactericida dos produtos naturais, visto que o efeito bacteriostático foi determinado pela ausência de crescimento nos poços da placa de microdiluição (Pozzatti et al., 2009). Após a semeadura, as placas de petri foram incubadas em estufa bacteriológica a $37^{\circ}$, por $24 \mathrm{~h}$. A CBM foi considerada a menor concentração que impediu o crescimento visível das bactérias ou permitiu a formação de até três Unidades Formadoras de Colônia (UFC). Assim, as concentrações em que se verificou a formação de mais de três UFC foram consideradas inibitórias ao crescimento bacteriano (CBM); enquanto as concentrações na qual se observou nulidade de crescimento ou menos de 3 UFC, foram consideradas bactericidas (Pozzatti et al., 2009). Todos os testes foram realizados em triplicata. RESULTADOS

QUADRO 1. Especificações técnicas dos óleos essenciais utilizados no estudo, segundo laudo técnico expedido por fornecedor.

\begin{tabular}{|c|c|c|c|}
\hline Óleo essencial & Densidade (g.mL $\left.\mathrm{mL}^{1}, 20^{\circ} \mathrm{C}\right)$ & Origem & Fitoconstituintes \\
\hline Cinnamomum cassia (Canela da China) & 0,912 & China & Aldeído cinâmico \\
\hline Ocimum basilicum (Manjericão) & 0,898 & Brasil & Linalol 1,8- cineol \\
\hline Thymus vulgaris (Tomilho) & 0,908 & França & Timol p-cimeno \\
\hline
\end{tabular}

Rev. Bras. PI. Med., Campinas, v.16, n.2, supl. I, p.372-377, 2014. 
Os valores da Concentração Inibitória Mínima (CIM) e Concentração Bactericida Mínima (CBM) dos produtos testados sobre as cepas de S. mutans e S. aureus estão apresentados, respectivamente, no Quadro 3 e Quadro 4. Não houve crescimento bacteriano no Controle de Esterilidade e Controle Positivo (Clorexidina), sendo este observado no Controle de Crescimento.

\section{DISCUSSÃO}

Diversos estudos mostram que os óleos essenciais apresentam efeito bactericida e bacteriostático contra variadas espécies de bactérias (Aquino et al., 2010; Costa et al., 2009; Freires et al., 2010, Martins et al., 2010), entretanto, há pouco relato quanto à ação dos óleos essenciais de Cinnamomum cassia, Ocimum basilicum e Thymus vulgaris sobre cepas de S. aureus e S. mutans. Almeida et al., 2012 mostrou o efeito desses produtos sobre Candida.

Os valores de CIM e CBM verificados no presente estudo demonstram que os produtos naturais avaliados apresentam propriedades biológicas ativas frente a inibição $S$. mutans e $S$. aureus. Conforme discutido por Menezes et al. (2009), produtos naturais apresentam atividade antimicrobiana adequada quando sua concentração inibitória é inferior a $100 \mathrm{mg} / \mathrm{mL}$. No presente estudo, a CIM e CBM dos óleos essenciais $C$. cassia e $T$. vulgaris apresentou valores muito baixos, o que indica elevada atividade antimicrobiana e corrobora o resultado de outros estudos (Almeida et al., 2012).

O Controle Positivo (Clorexidina), o Controle de Esterilidade e o Controle de Crescimento foram empregados de modo a validar a técnica utilizada neste estudo (Cavalcanti et al., 2010). A ausência de crescimento fúngico diante da Clorexidina demonstra a susceptibilidade das cepas frente a um antimicrobiano sintético. Dessa forma, ao considerar as diferenças entre a natureza química dos óleos essenciais e do Controle Positivo, não foi possível comparar os resultados obtidos por essas substâncias (Cavalcanti et al., 2010).

Costa et al., (2009), avaliaram a ação antimicrobiana do óleo essencial de Ocimum basilicum, o qual mostrou-se ativo sobre cepas bacterianas até a concentração de $2 \%$, diferindo do nosso estudo, em que mostrou-se ativo sobre cepas até $4 \%$, porém, em ambos os casos, verificou-se atividade bactericida e bacteriostática do produto. Aquino et al., verificou a atividade do óleo Ocimum basilicum contra 8 cepas diferentes de $S$. aureus e, em todas, o óleo apresentou ação bactericida e bacteriostática. Dentre elas, 5 foram inibidas e mortas com CIMs e CBMs de 3,12 e 6,25 $\mathrm{g} / \mathrm{mL}$, respectivamente, sendo esses menores que os dados encontrados em nosso estudo.

Machado et al., 2011, afirmaram que a linhagem ATCC 25923 de S. aureus possui alta suscetibilidade a diversos óleos essenciais, estando entre eles o Cinnamomum cassia e que, na técnica de Halos de Inibição, apresentou um halo de 15,5 $\mathrm{mm}$. Apesar da metodologia diferente, pode ser comparado a esta pesquisa quanto à presença ou ausência da atividade antibacteriana, mostrando que o óleo essencial de canela foi eficaz contra o $S$. aureus. Não encontramos relato na literatura quanto

QUADRO 3. Concentrações Inibitórias Mínimas (CIM) em $\mathrm{mg} / \mathrm{mL}$ dos óleos essenciais de Ocimum basilicum, Thymus vulgaris e Cinnamomum cassia frente à cepas de $S$. mutans e $S$. aureus.

\begin{tabular}{ccc}
\hline & \multicolumn{2}{c}{ Microorganismos } \\
\cline { 2 - 3 } Óleo Essencial & S. mutans & S. aureus \\
& CIM & CIM \\
& $\mathrm{mg} / \mathrm{mL}$ & $\mathrm{mg} / \mathrm{mL}$ \\
\hline Cinnamomum cassia & 1,125 & 0,5625 \\
Ocimum basilicum & 36,0 & 36,0 \\
Thymus vulgaris & 2,25 & 0,5625 \\
\hline
\end{tabular}

QUADRO 4. Concentração Bactericida Mínima (CBM) dos óleos essenciais de Ocimum basilicum, Thymus vulgaris e Cinnamomum cassia frente à cepas de S. mutans e S. aureus.

\begin{tabular}{ccc}
\hline & \multicolumn{2}{c}{ Microorganismos } \\
\cline { 2 - 3 } Óleo Essencial & S. mutans & S. aureus \\
& CBM & $\mathrm{CBM}$ \\
& $\mathrm{mg} / \mathrm{mL}$ & 0,5625 \\
\hline Cinnamomum cassia & 1,125 & 36,0 \\
Ocimum basilicum & Sem ação & 0,5625 \\
Thymus vulgaris & 2,25 & \\
\hline
\end{tabular}

Rev. Bras. PI. Med., Campinas, v.16, n.2, supl. I, p.372-377, 2014. 
à ação antibacteriana dos óleos Cinnamomum cassia e Ocimum basilicum sobre S. mutans.

Santos et al. (2007), avaliaram o óleo essencial de Thymus vulgaris através das técnicas de Concentração Inibitória Mínima e de Halos de Inibição e verificaram que este apresentou atividade considerável frente ao $S$. mutans, apresentando halos de inibição variando de 2 a $30 \mathrm{~mm}$ e CIM de $100 \mu \mathrm{g} / \mathrm{mL}$, sendo uma concentração maior comparada ao nosso estudo. Segundo SantosJunior (2010), o tomilho possui atividade frente ao S. aureus apresentando Concentração Inibitória Mínima de 0,39\%.

Apesar dos poucos relatos encontrados, o presente estudo corrobora os achados da literatura quanto à atividade inibitória dos óleos essenciais sobre $S$. aureus. No entanto não encontramos dados dos óleos Cinnamomum cassia e Ocimum basilicum sobre S. mutans. Diante dos resultados do nosso estudo quanto à ação antibacteriana, surgem possibilidades de utilizar os óleos essenciais de Cinnamomum cassia, Ocimum basilicum e Thymus vulgaris como agentes antimicrobianos.

\section{CONCLUSÃO}

Os óleos essenciais avaliados apresentaram ação antibacteriana frente a cepas de $S$. mutans e $S$. aureus, apresentando os menores valores de CIM e CBM os óleos C. cassia e T. vulgaris.

\section{REFERÊNCIA}

ALIGIANNIS, N.; KALPOUTZAKIS, E.; MITAKU, S.; CHINOU, J.B. Composition and Antimicrobial Activity of the Essential Oils of Two Origanum Species. Journal of Agricultural and Food Chemistry, v.49, n.9, p.416867, 2001.

ALMEIDA, L. F. D. ; CAVALCANTI, Y. W. ; CASTRO, R. D. ; LIMA, E. O. Atividade antifúngica de óleos essenciais frente amostras clínicas de Candida albicans isoladas de pacientes HIV positivos. Revista Brasileira de Plantas Medicinais (Impresso), v. 14, p. 649-655, 2012

AQUINO, L.C.L.; SANTOS, G.G.; TRINDADE, R.C.; ALVES, J.A.B.; SANTOS, P.O.; ALVES, P.B.; BLANK, A.F.; CARVALHO, L.M. Atividade antimicrobiana dos óleos essenciais de erva-cidreira e manjericão frente a bactérias de carnes bovinas. Alimentos e Nutrição Araraquara, v.21, n.4, p.529-535, 2010.

BERALDO CC, ANDRADE D. Higiene bucal com clorexidina na prevenção de pneumonia associada à ventilação mecânica. Jornal Brasileiro de Pneumologia, v.34, n.9, p.707-714, 2008.

CAVALCANTI, Y.W.; ALMEIDA, L.F.D.; PADILHA, W.W.N. Atividade antifúngica de três Óleos Essenciais sobre cepas de Candida. Revista Odontológica do Brasil Central, v.20, n.52, p.77-82, 2011

COSTA, C.M.G.R.; SANTOS, M.S.; BARROS, H.M.M.;
AGRA, P.F.M.; FARIAS, M.A.A. Efeito inibitório do óleo essencial de manjericão sobre o crescimento in vitro de Erwinia carotovora. Tecnologia \& Ciência Agropecuária, v.3, n.3, p.35-38, 2009.

DUARTE, M.C.T. Atividade Antimicrobiana de Plantas Medicinais e Aromáticas Utilizadas no Brasil. Disponível em: <http://www.multiciencia.unicamp.br/ artigos_07/a_05_7.pdf>. Acesso em: 01 de maio de 2012.

FREIRES, I.A.; ALVES, L.A.; JOVITO, V.C.; ALMEIDA, L.F.D.; CASTRO, R.D.; PADILHA, W.W.N. Atividades antibacteriana e antiaderente in vitro de tinturas de Schinus terebinthinfolius (Aroeira) e Solidago microglossa (Arnica) frente a bactérias formadoras do biofilme dentário. Odontologia Clínico Científica, v. 9, n.2, p.139-43, 2010.

LEITE GB. ANÁLISE DE PORTADORES ASSINTOMÁTICOS DE Staphylococcus aureus NO HOSPITAL UNIVERSITÁRIO DE BRASILIA, 2008. 101p. [Dissertação de mestrado]. Universidade de Brasília. Faculdade de Medicina, Brasília.

LIMA, I.O.; OLIVEIRA, R.A.G.; LIMA, E.O.; FARIAS N.M.P.; SOUZA, E.L. Atividade antifúngica de óleos essenciais sobre espécies de Candida. Revista Brasileira de Farmacognosia, v.16, n.2, p.197-201, 2006.

MACHADO, T.M.F.B.; BARBOSA, L.N.; PROBST, I.S.; FERNANDES JUNIOR, A. Ação antimicrobiana de óleos essenciais de uso em terapias naturais. 2011. 111p. [Dissertação de mestrado]. Universidade Estadual Paulista Júlio de Mesquita Filho, Botucatu, São Paulo.

MARTINS, A.G.L.A.; NASCIMENTO, A.R.; MOUCHREK FILHO, J.E.; MENDES FILHO, N.E.; SOUZA, A.G.; ARAGÃO, N.E.; SILVA, D.S.V. Atividade antibacteriana do óleo essencial do manjericão frente a sorogrupos de Escherichia coli enteropatogênica isolados de alfaces. Ciência Rural, v.40, n.8, p.1791-1796, 2010.

MENEZES, T.O.A.; ALVES A.C.B.A.; VIEIRA, J.M.S.; MENEZES, S.A.E.; ALVES, B.P.; MENDONÇA,L.C.V. Avaliação in vitro da atividade antifúngica de óleos essenciais e extratos de plantas da região amazônica sobre cepa de Candida albicans. Ver Odontol UNESP, v.38, p.184-191, 2009.

POZZO, M.D.; VIÉGAS, J.; SANTURIO, D.F.; ROSSATO, L.; SOARES, I.H.; ALVES, S.H.; COSTA, M.T. Atividade antimicrobiana de óleos essenciais de condimentos frente a Staphylococcus spp isolados de mastite caprina. Ciência Rural, v.41, n.4, p.667-672, 2011.

SANTOS-JÚNIOR, A.C.; SALIMENA, A.P.S.; MILLEZI, A.F.; PICCOLI, R.H. Avaliação da atividade antimicrobiana in vitro de óleos essenciais sobre Staphylococcus aureus. In: Anais da III Mostra Científica da ANPG, 2010, Rio de Janeiro.

SANTOS, R.S.I.; PEREIRA, D.F.A.; TEODORO, G.R.; CANETTIREI, A.C.V.; KHOURI, S.; SALVADOR, M.J. Avaliação da atividade antibacteriana e determinação da CIM do óleo essencial de Thymus vulgaris sobre Streptococcus mutans e caracterização química do óleo por cromatografia gasosa. In: XI Encontro Latino Americano de Iniciação Científica e VII Encontro Latino Americano de Pós-Graduação - Universidade do Vale do Paraíba, 2007, São Paulo.

SARTORATTO, A.; MACHADO, A.L.M.; DELARMELINA,

Rev. Bras. PI. Med., Campinas, v.16, n.2, supl. I, p.372-377, 2014. 
C.; FIGUEIRA, G.M.; DUARTE, M.C.T.; REHDER, V.L.G.; Composition and antimicrobial activity of essential oils from aromatic plants used in Brazil. Brazilian Journal of Microbiology, v.35, p.275-280, 2004.

SOARES, D.G.S.; OLIVEIRA, C.B.; LEAL, C.D.; MILANA, R.S.; PADILHA, W.W.N. Susceptibilidade in vitro de bactérias bucais a tinturas fitoterápicas. Revista Odonto Ciência, v. 21, n. 53, p.232-237, 2006
SOUZA, A.D.Z.; VARGAS, N.R.C.; MENDIETA, M.C.; HECK, R.M.; CEOLIN, T. Plantas medicinais utilizadas para cólicas menstruais: um desafio para a enfermagem. In: XIX CIC/II Mostra Científica, Pelotas-RS, 2010.

POZZATTI, P,; LORETO, E.S,; LOPES, P.G.M,; ATHAYDE, M.L,; SANTURIO, J.M,; ALVES, S.H.; Comparison of the susceptibilities of clinical isolates of Candida albicans and Candida dubliniensis to essential oils. Mycoses. 2009;53(1):12-5. 